\title{
Vibrio cholerae non-O1 bacteraemia: description of three cases in the Netherlands and a literature review
}

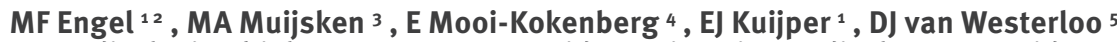

1. Medical Microbiology Department, Leiden University Medical Centre, Leiden, the Netherlands

2. De Hoogstraat rehabilitation centre, Utrecht, the Netherlands (current affiliation)

3. COMICRO, Expert Centre for Medical Microbiology, Hoorn, the Netherlands

4. Medical Microbiology Department, Izore, Centre for Infectious Diseases Friesland, Leeuwarden, the Netherlands

5. Department of Intensive Care Medicine, Leiden University Medical Centre, Leiden, the Netherlands

Correspondence: Madelon Frederique Engel (m.engel@dehoogstraat.nl)

Citation style for this article:

Engel MF, Muijsken MA, Mooi-Kokenberg E, Kuijper EJ, van Westerloo DJ. Vibrio cholerae non-01 bacteraemia: description of three cases in the Netherlands and a literature review. Euro Surveill. 2016;21(15):pii=30197. DOI: http://dx.doi.org/10.2807/1560-7917.ES.2016.21.15.30197

Article submitted on 13 April 2015 / accepted on 22 January 2016 / published on 14 April 2016

Vibrio cholerae non-01 serogroup (VCNO) bacteraemia is a severe condition with a high case-fatality rate. We report three cases diagnosed in the Netherlands, identified during a national microbiological congress, and provide a literature review on VCNO bacteraemia. A search strategy including synonyms for 'VCNO' and 'bacteraemia' was applied to PubMed, Medline, Web of Science and Embase databases. The three cases were reported in elderly male patients after fish consumption and/or surface water contact. The literature search yielded 82 case reports on 90 cases and six case series. Thirty case reports were from Asia (30/90; $33 \%$ ), concerned males (67/90; 74\%), and around one third (38/90; 42\%) involved a history of alcohol abuse and/or liver cirrhosis The presenting symptom often was gastroenteritis (47/90; $52 \%$ ) which occurred after seafood consumption in $32 \%$ of the cases (15/47). Aside from the most frequent symptom being fever, results of case series concurred with these findings. Published cases also included rare presentations e.g. endophthalmitis and neonatal meningitis. Based on the limited data available, cephalosporins seemed the most effective treatment. Although mainly reported in Asia, VCNO bacteraemia occurs worldwide. While some risk factors for VCNO were identified in this study, the source of infection remains often unclear. Clinical presentation may vary greatly and therefore a quick microbiological diagnosis is indispensable.

\section{Introduction}

The genus Vibrio is one of the six members of the Vibrionaceae family and includes ten species pathogenic to humans. Probably the most well-known species is Vibrio cholerae. Currently, there are over 130 known serogroups based on the presence of somatic $\mathrm{O}$ antigens $[1,2]$. Serogroup $\mathrm{O}_{1}$ and to a lesser extent 0139, is notorious for cholera outbreaks of dysenteric diarrhoea due to toxin production i.e. cholera toxin: ctx and toxin co-regulated pilus subunit A: tcpA. Infections are mostly confined to the gastro-intestinal tract [1].

In contrast, $V$. cholerae non-01 (VCNO) i.e. all serogroups except $\mathrm{O}_{1}$, rarely causes cholera-like outbreaks in form of mild diarrhoea due to toxin-producing VCNO strains but can cause severe extra intestinal infections such as wound infections and bacteraemia [3,4]. Cases of VCNO bacteraemia are reported in various countries and known risk factors are liver disease/cirrhosis and immunosuppression/immunocompromising conditions $[1,3,4]$. Sources of infection include seafood and contaminated water [5]. In the Netherlands, VCNO has indeed been isolated from recreational surface water (fresh and brackish) and sporadically from livestock $[5,6]$. In contrast, a Dutch study from 2010 showed that none of the examined shellfish tested positive for $V$. cholerae [7].

V. cholerae is a facultative anaerobic Gram-negative curved or comma-shaped motile bacillus. It can be isolated from blood by using standard culture media such as blood agar [1]. Biochemical properties of this organism include catalase positivity, oxidase positivity, sucrose fermentation and susceptibility for the vibriostatic compound 0129. Identification methods are various and include: matrix assisted laser desorption ionization-time-of-flight (MALDI-TOF) analyser (MALDITOF, Bruker corporation), VITEK systems (BioMerieux corporation) and polymerase chain reaction (PCR) for $16 \mathrm{~S}$ and target genes like toxR, ompW and sodB. The non-O1 serogroup can be distinguished from other serotypes by a lack of agglutination with 01-Ogawa and $01-$ Inaba antigen [1].

In 2013, a patient with a fulminant VCNO sepsis and extensive bullae on the lower extremities was admitted to the Leiden University Medical Centre (LUMC). When searching for literature on VCNO sepsis to help 


\section{FIGURE 1}

Flowchart with results from literature search for Vibrio cholera non-Olbacteraemia

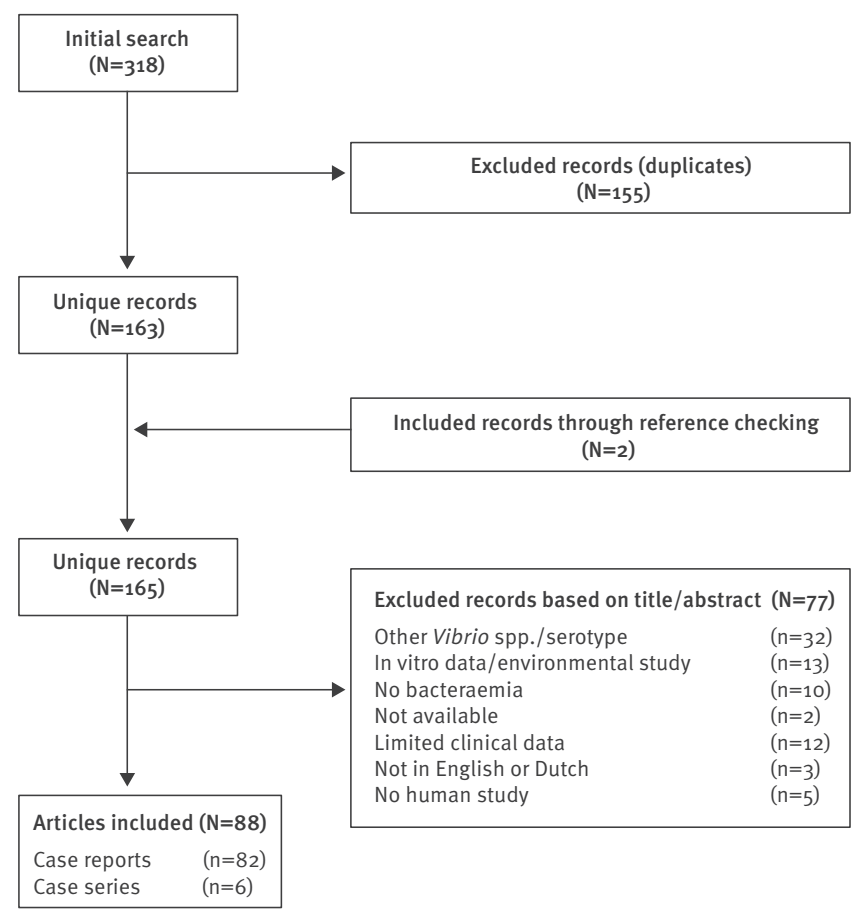

determine the source of infection and the optimal treatment strategy, we realised that the available literature appeared to be limited to case reports and small case series. In order to provide evidence for clinicians and public health experts about VCNO bacteraemia we report on a series of three cases and summarise the available literature on VCNO bacteraemia.

\section{Methods}

\section{Clinical case reports}

During the presentation of the LUMC case at the annual Dutch convention for medical microbiology, we inquired if any of the attending medical microbiologists was aware of additional cases of VCNO sepsis detected in the Netherlands. There is no mandatory notification for VCNO isolates in the Netherlands and VCNO sepsis is rare. Thus, retrieving VCNO sepsis cases detected in the Netherlands in another fashion was not feasible.

\section{Literature review}

In collaboration with an experienced information specialist of the LUMC library, we formulated a search strategy including synonyms for ' $V$. cholera non- $1_{1}$ ' and 'bacteraemia' and applied it to PubMed, Medline, Web of Science and Embase databases (Table 1). Articles published before 15 September 2014 were included. Additional articles were identified by checking the references of relevant articles and duplicates were excluded.
Retrieved articles were screened based on title and abstract, and exclusion criteria were: Vibrio spp. other than $V$. cholerae non- $0_{1}$, article not available through the journal's archive/the main author i.e. unanswered email after three months, in vitro data only, environmental samples only, no bacteraemia, no humans, limited clinical data, languages other than English or Dutch. No date limits were applied.

Data of individual case reports were merged and discussed as one patient group. Articles discussing case series were reported separately to prevent overlapping data. Extracted data included: patient demographics, medical history, risk factors i.e. exposure, clinical presentation, laboratory identification method, antimicrobial susceptibility, toxin production, samples cultured aside from blood, treatment and clinical outcome. If antimicrobial resistance was reported for 10 cases or more, they were reported in this article.

\section{Results}

\section{Clinical case reports}

In addition to the LUMC case, two additional cases were detected in different Dutch medical centres in 2006 and 2007. A relevant selection of the available data per case is presented; none of the isolates were tested for toxin production. All cases were men and above 50 years of age, with infections during the summer season.

\section{Case 1}

Case 1 was a man in his 50s, with a medical history of tuberculosis, chronic obstructive pulmonary disease, depression, marihuana and excessive alcohol use. One day prior to admission, he felt lethargic and developed a painful discoloration on his right ankle. Three days before hospital admission he had walked barefoot along the Dutch shoreline and ate a ready-made tuna salad. Upon admission at the emergency department (ED) he was hypothermic $\left(34.1^{\circ} \mathrm{C}\right.$, norm: 36.5 to37.5), blood pressure was 112/70 mmHg (norm: 120/80), heart rate 115 per minute (norm: 60 to 100), 02 saturation was 90\% without additional 02 (norm: 93 to 100). While in the ED he developed circulatory failure.

There were no abnormalities on chest auscultation. Inspection of the lower extremities showed oedema, blue discoloration and large bullae on both lower extremities. The chest X-ray showed patchy bilateral abnormalities of which the differential diagnosis comprised acute respiratory distress syndrome, bilateral pneumonia and pre-existing abnormalities after pulmonary tuberculosis.

Analysis of arterial blood at admission showed severe metabolic acidosis with respiratory compensation: $\mathrm{pH} 7.24$ (norm: 7.35 to 7.45), pCO2 $4.5 \mathrm{kPa}$ (norm: 4.5 to 6.0), $\mathrm{pO}_{2} 2.9 \mathrm{kPa}$ (norm: 10.6 to 13.3), base excess $-12.1 \mathrm{mmol} / \mathrm{L}$ (norm: -2 to 2 ), $\mathrm{O}_{2}$ saturation 30\% (norm: 94 to 99), glucose $1.3 \mathrm{mmol} / \mathrm{L}$ (norm: 3.5 


\section{FIGURE 2}

Cases of with Vibrio cholerae non-O1bacteraemia reported annually in Europe and worldwide, ( $\mathrm{n}=172$ including case reports and case series)

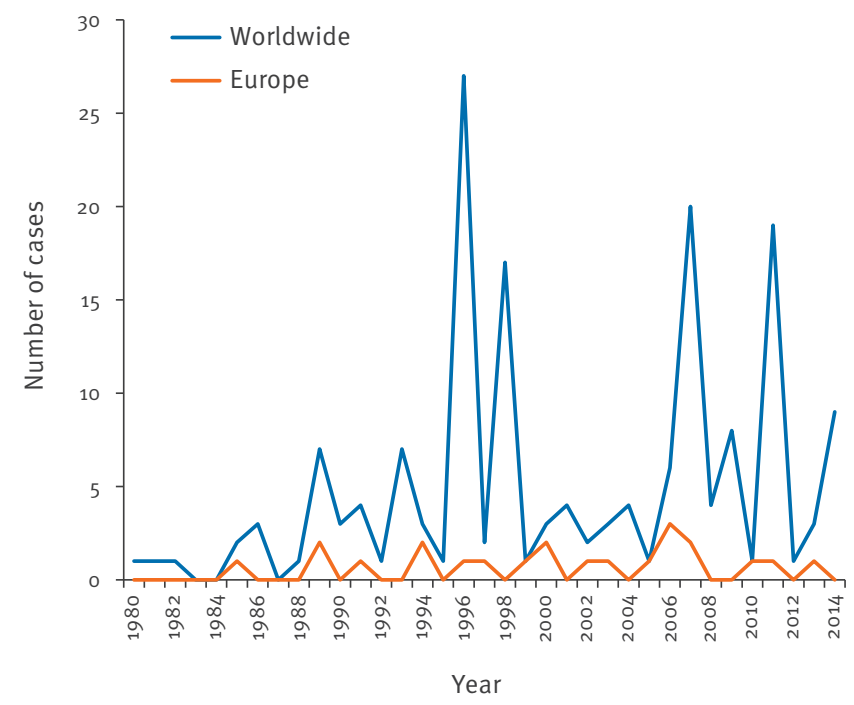

to 5.5), lactate $11.4 \mathrm{mmol} / \mathrm{L}$ (norm: 0.5 to 2.2). Blood analysis showed a leukopenia, a thrombopenia and elevated liver enzymes. Specifically relevant laboratory results were: haemoglobin $(\mathrm{Hb}) 8.8 \mathrm{mmol} / \mathrm{L}$ (norm: 8.5 to 11.0 ), leukocytes $2.82 \times 10^{9} / \mathrm{L}$ (norm: 4.00 to 10.00), thrombocytes $46 \times 10^{9} / \mathrm{L}$ (norm: 150 to 400 ), INR 1.7(norm 1), C-reactive protein (CRP) $85 \mathrm{mg} / \mathrm{L}$ (norm: 0.0 to 0.5 ), bilirubin $71 \mu \mathrm{mol} / \mathrm{L}$ (norm: 0 to 17 ), gammaglutamyltransferase (gamma-GT) $428 \mathrm{U} / \mathrm{L}$ (norm: o to 55), alkaline phosphatase (AF) $122 \mathrm{U} / \mathrm{L}$ (norm: 0-115), aspartate-aminotransferase (ASAT) $179 \mathrm{U} / \mathrm{L}$ (norm: 0 to 35), alanine-aminotransferase(ALAT) $68 \mathrm{U} / \mathrm{L}$ (norm: 0-45), creatinine was normal.

The putative diagnosis was septic shock due to deep skin infection. Empirical antimicrobial treatment with ciprofloxacin, cefotaxime and selective digestive decontamination with polymyxin $\mathrm{E}$, tobramycin and amphotericin B, was initiated, and the patient was resuscitated, started on vasopressors and admitted to the intensive care unit. Necrotising fasciitis was excluded upon surgical exploration. As VCNO non0139 was isolated from blood and bullae content on admission day 3, antimicrobial treatment was switched to ciprofloxacin and cefotaxime. On the eighth admission day, the patient developed multi-organ failure (MOF). With the working diagnosis 'hospital acquired infection', gentamicin and flucloxacillin were added. The next day, blood cultures showed Candida albicans and before additional treatment was started the patient died from MOF and sepsis. At post-mortem examination C. albicans and Aspergillus fumigatus, but no Vibrio spp. were cultured from several organs including lungs, spleen, liver and intestine.
Microbiology findings

Within 24 hours from presentation at the ED blood cultures and cultures of bullae content grew rod-shaped/ curved Gram-negative bacteria which were oxidase-, katalase- and DNase-positive. MALDI-TOF analysis showed $V$. albensis with a score of 2.0 which corresponds with a secure identification on genus level and probable identification on species level (norm: 2.0 to 2.3). Additional biochemical testing (i.e. API 20E, Biomerieux) indicated $V$. cholerae. The microorganism did not agglutinate with O1-Ogawa or O1-Inaba antisera, was sensitive to the vibriostatic compound $0 / 129$ and was therefore labelled VCNO. This finding was confirmed and supplemented i.e. non-O 139, by the Dutch National Institute for Public Health and Environment (RIVM). In house susceptibility testing by disk diffusion showed ciprofloxacin and co-trimoxazole sensitivity.

Cultures of the tuna salad packaging did not reveal any Vibrio spp.

Case 2

A man in his late 60 s with a medical history of heart disease, insulin-dependent diabetes mellitus type II, a cholecystectomy and an aneurysm of the abdominal aorta, presented to the ED with severe diarrhoea. Two weeks earlier, while on one of the Dutch islands, he suffered from severe diarrhoea for two days after having eaten raw herring. There was initial improvement, but the watery diarrhoea recurred and he consulted a general practitioner who referred him to hospital. There was no blood or mucus in his stool. He did not report any surface water contact.

Upon hospital admission, the patient was mildly icteric and had dyspnoea (respiratory rate 29/minute; norm: 12 to 18 ), lowered $\mathrm{O}_{2}$ saturation of $91 \%$ without supplemental oxygen. He was tachycardic (129/minute), blood pressure was slightly elevated $(132 / 92 \mathrm{mmHg})$ and he had a temperature of $38^{\circ} \mathrm{C}$. Aside from abdominal distention, physical examination of the abdomen, heart, lungs and skin on the extremities showed no abnormalities. Ultrasound scan of the abdomen showed no abnormalities except steatosishepatis and liver cysts ( $4 \mathrm{~cm}$ in diameter). The electrocardiogram and abdominal X-ray were normal. The chest X-ray revealed signs of congestive heart failure.

Parameters of the arterial blood analysis were within normal range. Other laboratory findings at admission showed a mild leucocytosis of $14.0 \times 10^{9} / \mathrm{L}$ (norm: 4 to 11) and elevated liver enzymes indicating cholestasis. Laboratory results included: $\mathrm{Hb} 9.0 \mathrm{mmol} / \mathrm{L}$, thrombocytes $226 \times 10^{9} / \mathrm{L}, \mathrm{CRP} 111 \mathrm{mg} / \mathrm{L}$ (norm: o to 10), glucose $12.0 \mathrm{mmol} / \mathrm{L}$ (norm: 3.5 to 7.8 ), sodium $137 \mathrm{mmol} / \mathrm{L}$ (norm: 135 to 145), potassium $3.4 \mathrm{mmol} / \mathrm{L}$ (norm: 3.5 to 5.0 ), creatinine $60 \mu \mathrm{mol} / \mathrm{L}$ (norm: 50 to 110 ), urea $5.3 \mathrm{mmol} / \mathrm{L}$ (norm: 2.5 to 7.5), LDH $269 \mathrm{U} / \mathrm{L}$ (norm: o to 250), ASAT $194 \mathrm{U} / \mathrm{L}$ (norm: o to 40), ALAT 292U/L, AF251 $\mathrm{U} / \mathrm{L}$ (norm: o to 120), gamma-GT $631 \mathrm{U} / \mathrm{L}$, bilirubin total $90 \mu \mathrm{mol} / \mathrm{L}$ (norm: o to 17 ), bilirubin direct $66 \mu \mathrm{mol} / \mathrm{L}$ 
TABLE 1

Literature search strategy for Vibrio cholera non-O1 bacteraemia

\begin{tabular}{|c|c|c|c|}
\hline Database & Query & All records & $\begin{array}{l}\text { Unique } \\
\text { records }\end{array}$ \\
\hline $\begin{array}{l}\text { PubMed/ } \\
\text { Medline }^{\mathrm{a}}\end{array}$ & 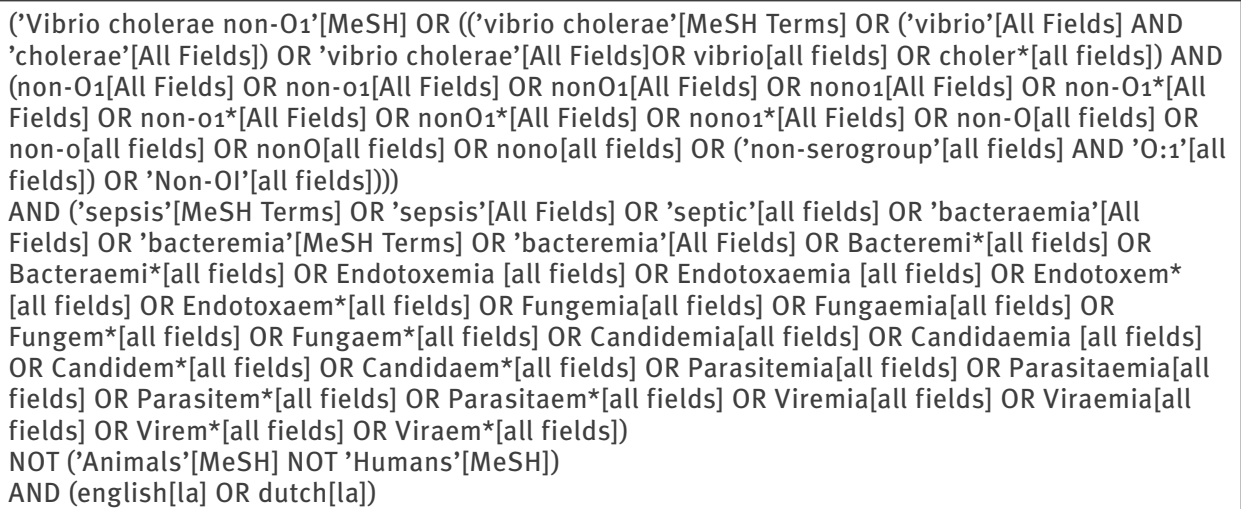 & 87 & 87 \\
\hline $\begin{array}{l}\text { Web of } \\
\text { Science }\end{array}$ & 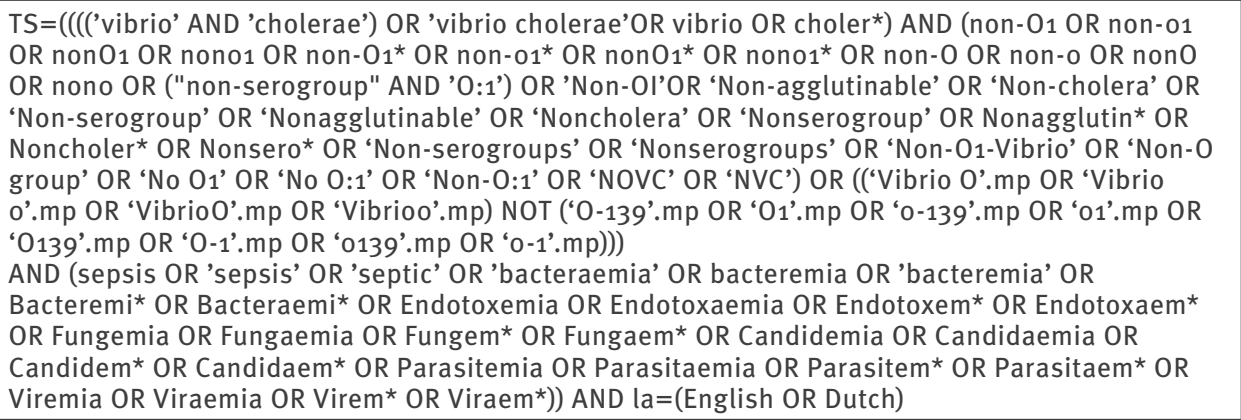 & 62 & 19 \\
\hline Embase & 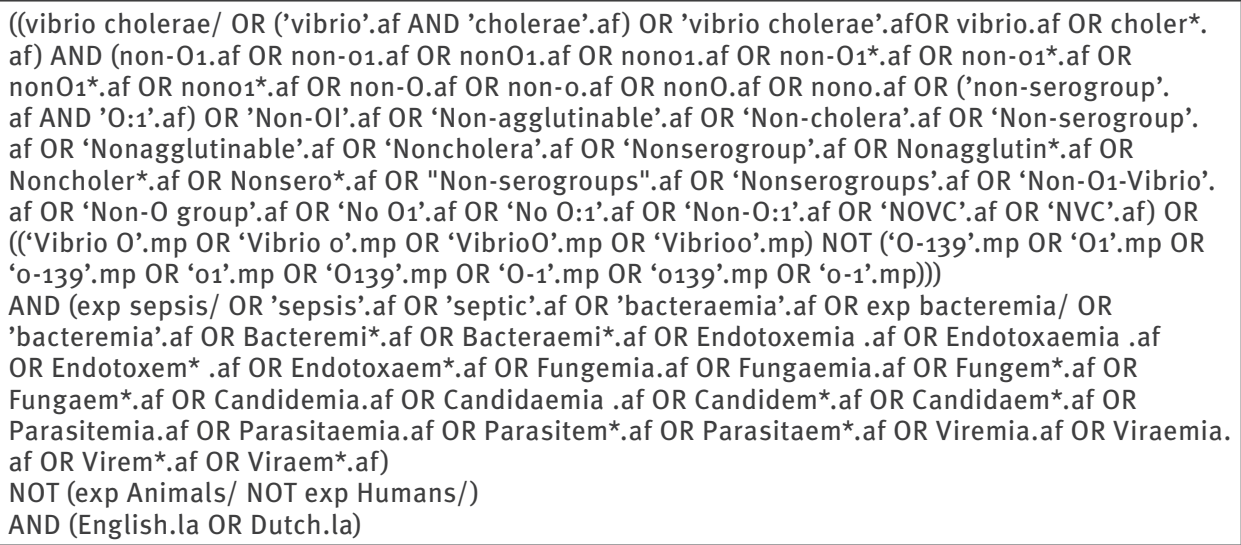 & 109 & 20 \\
\hline Science Direct & 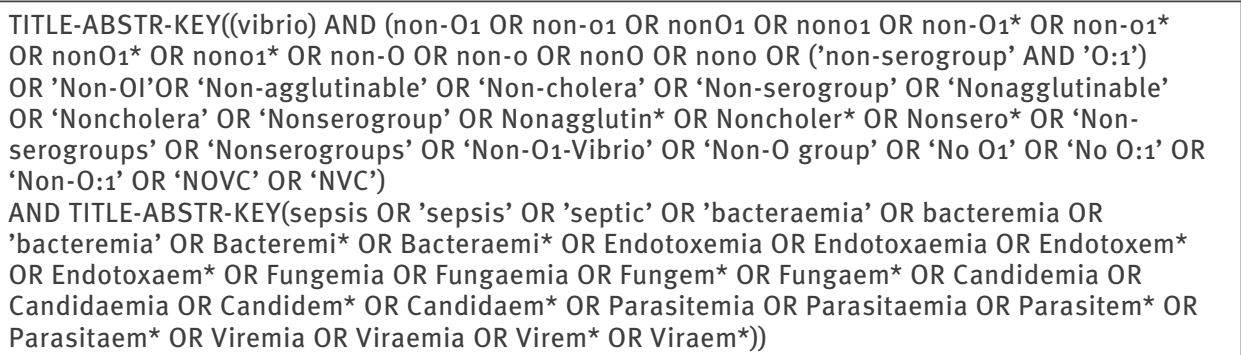 & 60 & 37 \\
\hline Total & & 318 & 163 \\
\hline
\end{tabular}

la: language; MeSH: medical subject headings; TS: title/summary.

a No additional records were retrieved through searching the Medline database after searching the PubMed database. 
(norm: o to 5), amylase $12 \mathrm{U} / \mathrm{L}$ (norm: o to 100), lipase $15 \mathrm{U} / \mathrm{L}$ (norm: o to 70 ) and lactate $2.3 \mathrm{mmol} / \mathrm{L}$ (norm: o to 1.8$)$.

The diagnosis was sepsis and after obtaining blood cultures, treatment with amoxicillin-clavulanic acid and gentamicin was initiated according to the local sepsis treatment protocol. On the second admission day, the Gram-negative rod was isolated and suspected to be Salmonella spp. Treatment was switched to co-trimoxazole. Later that day, as the isolate tested oxidase-positive, the working diagnosis was changed to Pseudomonas spp. and treatment was switched to ciprofloxacin. Ciprofloxacin was continued after the identification of $V$. cholerae. The patient recovered fully, was discharged after five days with oral ciprofloxacin, and returned to his island holiday.

\section{Microbiology findlings}

One day after hospital admission, blood cultures became positive with Gram-negative rods, later identified as $V$. cholerae (Phoenix Automated Microbiology System, BD diagnostics and API E, Biomerieux). The isolate was sent to the RIVM and the biochemical profile, fatty acid analysis and $16 \mathrm{~S}$ rDNA PCR showed $V$. cholerae non-01 non-0139. Stool cultures remained negative for Vibrio spp.. With standard disk diffusion the isolate tested susceptible to co-trimoxazole, cefuroxime, gentamicin, ciprofloxacin, piperacillin, ceftazidime, meropenem, tobramycin and piperacillin/ tazobactam. It was intermediately sensitive to amoxicillin, amoxicillin-clavulanic acid, cefazolin and resistant to ceftriaxone.

Case 3

A man in his early 70 s presented at the ED with general malaise, dizziness, decreased appetite, coughing and dyspnoea that had been lasting for one week. Relevant medical history comprised heart failure and a hepatojejunostomy for chronic cholangitis more than a decade before presentation. He had not been travelling or swimming, but habitually caught eel in the ljsselmeer lake that summer and cleaned the eel himself. He did not report having consumed the eel or having had contact with lake water other than taking eel out of fishing nets, or of wounds or lacerations on his hands before his illness.

Upon hospital admission, he had a temperature of $39^{\circ} \mathrm{C}$, heart rate of $66 /$ minute, blood pressure of $110 / 70 \mathrm{~mm} /$ $\mathrm{Hg}$ and oxygen saturation was normal without oxygen administration. He was disorientated and had trouble concentrating. There were no signs of gastroenteritis or abnormalities on chest examination. No apparent skin lesions were reported.

Arterial blood analysis showed a pH 7.46, pCO2 4.4 $\mathrm{kPa}$ (norm: 4.7 to 6.4 ), bicarbonate $23.1 \mathrm{mmol} / \mathrm{L}$ (norm: 22.0 to 29.0), pO2 $6.4 \mathrm{kPa}$ (norm: 10.0 to 13.3), base excess $0.1 \mathrm{mmol} / \mathrm{L}$ (norm: -3.0 to 3.0), 02 saturation $86 \%$. Analysis of venous blood showed raised inflammatory parameters, impaired renal and liver function tests. CRP $181 \mathrm{mg} / \mathrm{L}$ (norm: < 7), leukocytes $10.6 \times 10^{9} / \mathrm{L}$, urea $12,5 \mathrm{mmol} / \mathrm{L}$ (norm: 2.9 to 7.5 ), creatinin $115 \mathrm{umol} / \mathrm{L}$ (norm: 01 to 05), AP $336 \mathrm{U} / \mathrm{L}$ (norm: o to 120), gamma-GT $282 \mathrm{U} / \mathrm{L}$, bilirubin $70 \mathrm{umol} / \mathrm{L}$ (norm: o to 20), ASAT $132 \mathrm{U} / \mathrm{L}$ (norm: o to 32), ALAT $104 \mathrm{U} / \mathrm{L}$, glucose $7.9 \mathrm{mmol} / \mathrm{L}$ (norm: o to 7.8 ).

The patient was initially empirically treated for sepsis with ceftriaxone and gentamicin, then switched to oral amoxicillin-clavulanic acid. He recovered completely and was discharged after seven days of hospitalisation.

\section{Microbiology findings}

Within 24 hours after admission, blood cultures grew Gram-negative rods. On TCBS agar, yellow colonies appeared which tested oxidase negative. Identification through API NE (Biomerieux corporation) showed $V$. cholerae (code 7074745, ID 99.0\%), which was confirmed with $16 \mathrm{~S}$ PCR. The isolate's susceptibility was tested using standard disk diffusion on Muller Hinton agar plates. It was susceptible to amoxicillin, amoxicillin-clavulanic acid, piperacillin, piperacillin-tazobactam, cefoxitin, ceftazidime, meropenem, gentamicin.

Sputum cultures were negative for Vibrio spp.. The eel were not examined microbiologically, therefore the source of infection remained unclear.

\section{Review}

The initial search yielded 163 unique articles and 155 duplicates (Figure 1). Reference checking resulted in identification of two additional unique articles. Of the 165 retrieved articles, 77 were excluded based on title or abstract, leaving 88 articles including 82 case reports [8-89] and six articles reporting case series [90-95].

\section{Case reports}

The 82 articles retrieved covered 90 patients; 23 (26\%) of them were female and the mean age was $49(0-84)$ years. Cases were reported worldwide; 22 (25\%) were identified in Europe, 19 (21\%) in the United States of America, 30 (33\%) in the Asian continent and 19 (21\%) in the remaining continents. The remaining case characteristics are presented in Table 2 (extraction table for data available from authors upon request).

The most frequently reported symptom was gastroenteritis $(51 / 90 ; 57 \%)$ followed by fever without gastroenteritis (26/90; 29\%) and bullae (18/90; 20\%). However, also rare presentations such as endophthalmitis and neonatal meningitis were reported. Overall known risk factors such as consumption or handling of seafood or consumption or contact with possibly contaminated water were reported in 45 cases (45/90; $50 \%)$. Of the 47 patients (47/90; 52\%) presenting with gastroenteritis and no bullae, $15(15 / 47)$ reported prior seafood consumption, five $(5 / 47)$ reported fishing (possibly implying consumption) and for nine cases (9/47) no exposure data were reported; no information 
TABLE 2

Characteristics of clinical cases with Vibrio cholerae non-O1 bacteraemia $(n=3)$, and published case reports $(n=90)$ and case series $(n=82)$ identified through literature research

\begin{tabular}{|c|c|c|c|c|}
\hline \multirow{3}{*}{ Characteristics } & & \multirow{2}{*}{$\begin{array}{l}\text { Dutch cases } \\
\qquad(n=3)\end{array}$} & \multicolumn{2}{|c|}{ Literature review } \\
\hline & & & $\begin{array}{l}\text { Case reports } \\
\quad(n=90)\end{array}$ & $\begin{array}{l}\text { Case reports } \\
\quad(n=82)\end{array}$ \\
\hline & & \multicolumn{3}{|c|}{ Number (\%) or mean (min-max) } \\
\hline \multirow{2}{*}{ Demographics } & Female $^{a}$ & 0 & $23(26)$ & $12(15)$ \\
\hline & Age & $65(57-72)$ & $49(0-84)$ & NR $(28-83)$ \\
\hline \multirow{4}{*}{ Origin } & Europe & 3 & $22(25)$ & 0 \\
\hline & United States of America & 0 & $19(21)$ & 0 \\
\hline & Asia & 0 & $30(33)$ & $74(90)$ \\
\hline & Other $^{c}$ & 0 & $19(21)$ & $6(7)$ \\
\hline \multirow{5}{*}{ Medical history } & Uneventful & 0 & $12(13)$ & NR \\
\hline & Liver cirrhosis and/or alcohol abuse & 1 & $38(42)$ & $27(33)$ \\
\hline & Liver or bile duct disease (including cholecystectomy) & 2 & $6(7)$ & $7(9)$ \\
\hline & Immunocompromised $^{d}$ & 0 & $14(16)$ & NR \\
\hline & Not provided & 0 & $6(7)$ & NR \\
\hline \multirow{6}{*}{ Risk factors } & Consumption of seafood & 2 & $21(23)$ & $12(15)$ \\
\hline & Surface water contact & 1 & $8(9)$ & $3(4)$ \\
\hline & Surface water contact and seafood handling (e.g. fishing) & 1 & $11(12)$ & $8(10)$ \\
\hline & Consumption of possibly contaminated water & 0 & $5(6)$ & NR \\
\hline & Other risk factors ${ }^{\mathrm{e}}$ & 0 & $5(6)$ & NR \\
\hline & Not provided & 0 & $15(17)$ & NR \\
\hline \multirow{4}{*}{$\begin{array}{l}\text { Symptoms at } \\
\text { presentation }\end{array}$} & $\begin{array}{l}\text { Gastroenteritis (nausea and abdominal pain/vomiting/mild } \\
\text { diarrhoea) }\end{array}$ & 1 & $47(52)$ & 32 (39) \\
\hline & Fever, no gastroenteritis & 1 & $26(29)$ & $51(62)$ \\
\hline & Bullae & 1 & $14(17)$ & $8(10)$ \\
\hline & Bullae and gastroenteritis & 0 & $4(4)$ & NR \\
\hline \multirow{5}{*}{ Vibrio cholerae isolated ${ }^{b}$} & Faeces & 0 & 5 of 32 & o of 19 \\
\hline & Ascites/peritoneal fluid & 0 & 8 of 20 & 8 of 33 \\
\hline & Food or water & 0 & 5 of 7 & 2 of 2 \\
\hline & CSF (meningitis) & 0 & 3 of 5 & NR \\
\hline & Bulla fluid & 1 of 1 & 6 of 6 & NR \\
\hline \multirow{4}{*}{ Clinical outcome } & Recovery & 2 & $56(62)$ & $51(62)$ \\
\hline & Irreversible trauma (e.g. severe neurological impairment) & 0 & $2(2)$ & NR \\
\hline & Death & 1 & $31(34)$ & $29(35)$ \\
\hline & Unknown & 0 & $1(2)$ & NR \\
\hline
\end{tabular}

CSF: cerebrospinal fluid; NR: Not reported or insufficient data.

a The sex of one patient (newborn) was not provided.

${ }^{\mathrm{b}}$ Aside from positive blood cultures which were confirmed for all cases.

c Australia, Israel, Kuwait, Lebanon, Mauritius, Ottawa (Canada), Puerto Rico, Qatar, Saudi Arabia.

d AIDS/HIV, chemotherapy, prednisone, neutropenia, non-Hodgkin lymphoma, myelodysplastic syndrome, idiopathic aplastic anaemia, transplant recipient.

e Vibrio cholerae vaccine, baby bath/bottle contamination with raw seafood.

on exposure was available for the remaining 18 cases. In five cases (5/90; 6\%) authors hypothesised on additional risk factors such as indirect contact with raw seafood e.g. contaminated baby bathwater/bottle (2/5) and administration of the oral $V$. cholerae vaccine $(3 / 5)$. However, the vaccine contains killed whole $V$. cholera cells with or without recombinant B-sub unit and the nature of the alleged link to VCNO infection was not clarified by the authors. As our case definition of VCNO sepsis included bacteraemia, a positive blood culture was reported for all patients. Additional samples that were positive for VCNO are shown in Table 2. Thirtyone patients died due to their VCNO infection, which results in an overall case-fatality rate of 348 per 1,000 for this selected sample.

For 62 cases $(62 / 90 ; 69 \%)$, susceptibility data of the $V$. cholerae non-01 isolates were provided (extraction table available from authors upon request). Overall, in vitro resistance was observed to amoxicillin (4/50 
tested (intermediately) resistant), trimethoprim-sulfamethoxazole (4/37), ciprofloxacin (2/24), gentamicin (1/37) and doxycycline (3/38). Antimicrobials to which $V$. cholerae non-01 isolates appeared to be susceptible in vitro, without exception, were cephalotin $(n=14$ tested), cefuroxime $(n=10)$, cefotaxime $(n=14)$, ceftazidime $(n=12)$, ceftriaxone $(n=15)$, amikacin $(n=17)$ and chloramphenicol $(n=33)$. Toxin production of the isolates was not consistently reported in literature and therefore not included in the analysis.

\section{Case series}

Details of the six retrieved case series were extracted and analysed briefly given the selected nature of the sample (Table 2). Altogether, 82 patients with VCNO bacteraemia were retrieved, the majority of reports originating from the Asian continent. As in the three case reports described above, most patients were male. In contrast, fever was the most frequent presenting symptom and risk factors could be identified in only a minority of patients (24/82; $29 \%)$.

Overall, the number of cases reported peaked in 1996, 1998, 2007 and 2011 (Figure 2).

\section{Discussion}

We presented three cases of VCNO bacteraemia that were identified in the Netherlands between 2006 and 2013as well as 172 cases from literature occurring between 1980 and 2014. Corresponding with current knowledge, both the recently identified cases and the previously reported ones show that patients are typically male, often have a history of liver/bile duct disease and the presenting symptoms often include gastroenteritis, fever and bullae [1]. The suspected sources while seldom confirmed microbiologically, are commonly fish and surface water. In contrast to previous reports, however, we found that a great variety in clinical presentation does occur, ranging from lethargy to meningitis, endophthalmitis, cough and dyspnoea [1]. Severe outcomes include neurological impairment, lower limb amputation and death. All three Dutch cases presented during summer, the season of recreational activities such as fishing, swimming and of flourishing microorganisms in surface waters due to rising temperatures [96-98].

A major strength of our analysis is that it provides a complete overview of what is known about VCNO bacteraemia, whereas other reports merely describe individual cases or a selection of case reports. The search was formulated by an experienced scientist (MFE) and an information specialist (JS) and articles were provided by the LUMC library which has access to over 9,000 leading (bio-)medical journals. Therefore, we consider that this review includes all relevant published articles published in Dutch and English and provides a complete overview of the available literature on VCNO bacteraemia.
The summary of data on antimicrobial susceptibility provided here may assist physicians in choosing an adequate treatment regimen. The data indicate that administration of a cephalosporin is likely to be the best option when dealing with VCNO bacteraemia. However, an important factor that hinders the extrapolation of our data to clinical practice is publication bias, many authors did not report susceptibility data. This is crucial when evaluating resistance data, as many authors solely reported the susceptibility to antimicrobials administered to the patient in question. Additional relevant data on antimicrobial resistance that may very well have been available to the authors was not published.

After searching current literature for the aetiology of VCNO bacteraemia, we could not reveal why males are affected more frequently than females, but found a similar trend in infections with other Vibrio spp [99]. The role of immunocompromising conditions in acquiring VCNO bacteraemia seems clear and the influence of liver cirrhosis can probably be attributed to high ferritin levels which are required for the metabolism of Vibrio spp [100].

Aside from predisposing conditions and exposure, bacterial virulence may very well play a significant role in the pathogenesis of VCNO bacteraemia. VCNO toxins are being studied and several are known e.g. ctx; large excretion of fluids and electrolytes into the lumen hly$\mathrm{AET}$; hemolysin, rtxA; actin cross linking, hap; haemagglutinin protease, type 3 and 6 secretion system, nanH; neuraminidase, NAG-ST; heat-stable enterotoxin. The clinical significance of these toxins (e.g. their role in bulla formation, remains yet to be determined [101,102].

In conclusion, VCNO bacteraemia is a disease that can be fatal and poses a threat around the globe especially to patients with a history of alcohol abuse and/or liver cirrhosis. Physicians should be aware of the possibility of VCNO bacteraemia in patients presenting with gastroenteritis, fever or bullae after consumption of or contact with seafood or potentially contaminated water. However, risk factors often remain unidentified, the clinical presentation varies greatly and a quick microbiological diagnosis is indispensable. Cephalosporins are likely the best treatment option for VCNO bacteraemia.

\section{Acknowledgements}

We gratefully acknowledge the assistance of Mr. J. Schoones, MA, experienced information specialist at the Walaeus library at the LUMC, with the literature search.

\section{Conflict of interest}

None declared. 


\section{Authors' contributions}

Madelon F. Engel: performing the literature review, gathering information on individual cases, drafting and revising the manuscript. Mariette A. Muijsken: provide information on one of the three cases, revising the manuscript. Esther Mooi-Kokenberg: provide information on one of the three cases, revising the manuscript. Ed J. Kuijper: revising the manuscript. David J. van Westerloo: provide information on one of the three cases, intensively revising the manuscript.

\section{References}

1. Versalovic J, Carroll KC, Funke G, Jorgensen JH, Landry ML, Warnock DW. Manual of clinical microbiology. Washington, DC: ASM Press; 2011

2. Centers for Disease Control and Prevention (CDC). CDC Laboratory Methods for the Diagnosis of Vibrio cholerae. Laboratory Methods for the Diagnosis of Vibrio cholerae. Ch 6. Atlanta: CDC. [Accessed 13 Apr 2016]. Available from: http://www.cdc.gov/cholera/pdf/Laboratory-Methods-for-theDiagnosis-of-Vibrio-cholerae-chapter-6.pdf

3. Centers for Disease Control and Prevention (CDC),DíazQuiñonez A, Hernández-Monroy I, Montes-Colima N, MorenoPérez A, Galicia-Nicolás A, Martínez-Rojano H, et al. . Outbreak of Vibrio cholerae serogroup 01 , serotype Ogawa, biotype El Tor strain--La Huasteca Region, Mexico, 2013.MMWR Morb Mortal Wkly Rep. 2014;63(25):552-3.PMID: 24964882

4. Haley BJ, Choi SY, Grim CJ, Onifade TJ, Cinar HN, Tall BD, et al. Genomic and phenotypic characterization of Vibrio cholerae non-O1 isolates from a US Gulf Coast cholera outbreak. PLoS One. 2014;9(4):e86264. DOI: 10.1371/journal.pone.0086264 PMID: 24699521

5. Schets FM, van den Berg HH, Marchese A, Garbom S, de Roda Husman AM. Potentially human pathogenic vibrios in marine and fresh bathing waters related to environmental conditions and disease outcome.Int J Hyg Environ Health. 2011;214(5):399 406. DOI: 10.1016/j.ijheh.2011.05.003 PMID: 21664866

6. Visser IJ, ter Laak EA, van Dijk NW, Wouda W. Toxigenic Vibrio cholerae non-0:1 isolated from a goat in The Netherlands. Vet Q. 1991;13(2):114-8. DOI: 10.1080/01652176.1991.9694293 PMID: 1882490

7. Schets FM, van den Berg HH, Rutjes SA, de Roda Husman AM. Pathogenic Vibrio species in dutch shellfish destined for direct human consumption.J Food Prot. 2010;73(4):734-8.PMID: 20377964

8. Albuquerque A, Cardoso H, Pinheiro D, Macedo G. Vibrio cholerae non-0139 and non-139 infection in hepatitis $C$ cirrhosis: A rare event. American Journal of Gastroenterology. 2011 Oct; Conference (var.pagings):S280.

9. Anderson AM, Varkey JB, Petti CA, Liddle RA, Frothingham R, Woods CW. Non-01 Vibrio cholerae septicemia: case report, discussion of literature, and relevance to bioterrorism. Diagn Microbiol Infect Dis. 2004;49(4):295-7. DOI: 10.1016/j. diagmicrobio.2004.04.016 PMID: 15313536

10. Berghmans T, Crokaert F, Sculier JP. Vibrio cholerae bacteremia in a neutropenic patient with non-small-cell lung carcinoma. Eur J Clin Microbiol Infect Dis. 2002;21(9):676-8. DOI: 10.1007/ S10096-002-0794-1 PMID: 12373501

11. Blanche P, Sicard D, Sevali Garcia J, Paul G, Fournier JM. Septicemia due to non-0:1 Vibrio cholerae in a patient with AIDS.Clin Infect Dis. 1994;19(4):813. DOI: 10.1093/ clinids/19.4.813 PMID: 7803670

12. Burns KD, Yurack J, McIntyre RW. Non-Ol vibrio cholerae septicemia associated with a motor vehicle accident.CMAJ. 1989;140(11):1334-5.PMID: 2720517

13. Chan HL, Ho HC, Kuo TT. Cutaneous manifestations of non-01 Vibrio cholerae septicemia with gastroenteritis and meningitis.J Am Acad Dermatol. 1994;30(4):626-8. DOI: 10.1016/S0190-9622(94)70071-o PMID: 8157789

14. Chan MR, Pirsch JD. Nonserogroup $0_{1}$ Vibrio cholerae in a renal transplant patient.Transplantation. 2007;83(5):668-9. DOI: 10.1097/01.tp.0000255321.86183.47 PMID: 17353792

15. Chang-Chien $\mathrm{CH}$. Bacteraemic necrotizing fasciitis with compartment syndrome caused by non-01 Vibrio cholerae.J Plast Reconstr Aesthet Surg. 2006;59(12):1381-4. DOI: 10.1016/j.bjps.2006.06.002 PMID: 17113524

16. Chang-Chien $\mathrm{CH}$, Ding HT, Liu C, Yang CS. Vibrio infection associated with finning injury of the hand.Injury. 2007;38(5):614-8. DOI: 10.1016/j.injury.2006.04.134 PMID: 16945371

17. Cheng NC, Tsai JL, Kuo YS, Hsueh PR. Bacteremic necrotizing fasciitis caused by Vibrio cholerae serogroup 056 in a patient with liver cirrhosis.J Formos Med Assoc. 2004;103(12):935-8. PMID: 15624044

18. Choi SM, Lee DG, Kim MS, Park YH, Kim YJ, Lee S, et al. Bacteremic cellulitis caused by non-01, non-0139 Vibrio cholerae in a patient following hematopoietic stem cell transplantation. Bone Marrow Transplant. 2003;31(12):1181-2. DOI: 10.1038/sj.bmt.1704044 PMID: 12796802

19. Chong Y, Kwon OH, Lee SY, Kim BS, Min JS. Non-O group 1 Vibrio cholerae septicemia and peritonitis--report of two cases. Yonsei Med J. 1985;26(1):82-4. DOI: 10.3349/ymj.1985.26.1.82 PMID: 4072273

20. Christenson B, Soler M, Nieves L, Souchet LM. Septicemia due to a non-0:1, non-0:139 Vibrio cholerae.Bol Asoc Med P R. 1997;89(1-3):31-2.PMID: 9168634

21. Couzigou C, Lacombe K, Girard P-M, Vittecoq D, Meynard J-L. Non-0:1 and non-0:139 Vibrio cholerae septicemia and pyomyositis in an immunodeficient traveler returning from Tunisia.Travel Med Infect Dis. 2007;5(1):44-6. DOI: 10.1016/j. tmaid.2006.06.002 PMID: 17161319

22. Dalsgaard A, Forslund A, Hesselbjerg A, Bruun B. Clinical manifestations and characterization of extra-intestinal Vibrio cholerae non-01, non-0139 infections in Denmark. Clin Microbiol Infect. 2000;6(11):625-7. DOI: 10.1046/j.14690691.2000.00174.x PMID: 11168070

23. de Groot R, van der Horst-Bruinsma IE, Janssens AR, Petit PL. [Sepsis caused by non-01-Vibrio cholerae: a patient in The Netherlands]. Ned Tijdschr Geneeskd. 1994;138(17):873-5. PMID: 8183400

24. Deris ZZ, Leow VM, Wan Hassan WM, Nik Lah NA, Lee SY, Siti Hawa $\mathrm{H}$, et al. Non-01, non-0139 Vibrio cholerae bacteraemia in splenectomised thalassaemic patient from Malaysia. Trop Biomed. 2009;26(3):320-5.PMID: 20237446

25. Dhar R, Ghafoor MA, Nasralah AY. Unusual non-serogroup $0_{1}$ Vibrio cholerae bacteremia associated with liver disease.J Clin Microbiol. 1989;27(12):2853-5.PMID: 2592546

26. Dhar R, Badawi M, Qabazard Z, Albert MJ. Vibrio cholerae (non-01, non-0139) sepsis in a child with Fanconi anemia. Diagn Microbiol Infect Dis. 2004;50(4):287-9. DOI: 10.1016/j. diagmicrobio.2004.08.004 PMID: 15582302

27. El-Hiday AH, Khan FY, Al Maslamani M, El Shafie S. Bacteremia and spontaneous bacterial peritonitis due to Vibrio cholerae (non-01 non-0139) in liver cirrhosis.Indian J Gastroenterol. 2006;25(2):107.PMID: 16763354

28. Eltahawy AT, Jiman-Fatani AA, Al-Alawi MM. A fatal non-01 Vibrio cholerae septicemia in a patient with liver cirrhosis. Saudi Med J. 2004;25(11):1730-1.PMID: 15573214

29. Farina C, Luzzi I, Lorenzi N. Vibrio cholerae $0_{2}$ sepsis in a patient with AIDS.Eur J Clin Microbiol Infect Dis. 1999;18(3):203-5. DOI: 10.1007/S100960050259 PMID: 10357055

30. Farmachidi JP, Sobesky R, Boussougant Y, Quilici ML, Coffin B. Septicaemia and liver abscesses secondary to non-O1/ non-0139 Vibrio cholerae colitis. Eur J Gastroenterol Hepatol. 2003;15(6):699-700. DOI: 10.1097/00042737-20030600000018 PMID: 12840683

31. Feghali R, Adib SM. Two cases of Vibrio cholerae non-01/ non-0139 septicaemia with favourable outcome in Lebanon. East Mediterr Health J. 2011;17(8):722-4.PMID: 21977578

32. Fernández-Natal I, Alcoba-Leza M. Non-O1 Vibrio cholerae bacteraemia without diarrhoea.Lancet. 1996;348(9019):67. DOI: 10.1016/S0140-6736(05)64401-7 PMID: 8691963

33. Fernández JM, Serrano M, De Arriba JJ, Sánchez MV, Escribano E, Ferreras P. Bacteremic cellulitis caused by Non-01, Non0139 Vibrio cholerae: report of a case in a patient with hemochromatosis.Diagn Microbiol Infect Dis. 2000;37(1):77-80. DOI: $10.1016 /$ S0732-8893(99)00153-4 PMID: 10794945

34. George N, Fredrick F, Mohapatra A, Veeraraghavan B, Kakde $\mathrm{ST}$, Valson AT, et al. Non-01, non-0139 Vibrio cholerae sepsis in a patient with nephrotic syndrome. Indian J Nephrol. 2013;23(5):378-80. DOI: 10.4103/0971-4065.116329 PMID: 24049279

35. Halabi M, Haditsch M, Renner F, Brinninger G, Mittermayer $H$. Vibrio cholerae non-01 septicaemia in a patient with liver cirrhosis and Billroth-II-gastrectomy.J Infect. 1997;34(1):83-4. DOI: 10.1016/S0163-4453(97)80016-3 PMID: 9120332

36. Heath CH, Garrow SC, Golledge CL. Non-O1 Vibrio cholerae: a fatal cause of sepsis in northern Australia.Med J Aust. 2001;174(9):480-1.PMID: 11386599

37. Hsieh YH, Chan CC, Wang SS, Chiang JH, Chou DY, Chang FY, et al. Recurrent spontaneous bacterial empyema in cirrhosis: a case report. Zhonghua Yi Xue Za Zhi (Taipei). 1998;61(7):421-6. PMID: 9699395

38. Huhulescu S, Indra A, Feierl G, Stoeger A, Ruppitsch W, Sarkar B, et al. Occurrence of Vibrio cholerae serogroups other than $\mathrm{O}_{1}$ and $\mathrm{O}_{139}$ in Austria. Wien Klin Wochenschr. 
2007;119(7-8):235-41. DOI: 10.1007/s00508-006-0747-2 PMID: 17492351

39. Inoue T, Kitai S, Hayaishi S, Kudo M. Septicemia due to Vibrio cholerae serogroup non-01/non-0139 strain in a cirrhotic patient.Clin J Gastroenterol. 2012;5(6):383-7. DOI: 10.1007/ S12328-012-0332-3 PMID: 26181318

40. Ismail EA, Shafik MH, Al-Mutairi G. A case of non-0:1 Vibrio cholerae septicemia with meningitis, cerebral abscess and unilateral hydrocephalus in a preterm baby. Eur J Clin Microbiol Infect Dis. 2001;20(8):598-600. DOI: 10.1007/S100960100553 PMID: 11681447

41. Issack MI, Appiah D, Rassoul A, Unuth MN, Unuth-Lutchun N. Extraintestinal Vibrio infections in Mauritius.J Infect Dev Ctries. 2008;2(5):397-9. DOI: 10.3855/jidc.205 PMID: 19745511

42. Kambal AMM, Ajarim DS, Fawzy E, Babay HH, Chowdhury MNH. Septicemia caused by a non-01 Vibrio cholerae.Ann Saudi Med. 1996;16(2):200-2.PMID: 17372457

43. Kerketta JA, Paul AC, Balaji V,, Kirubakaran VB, Jesudason MV, Moses PD. Non-01 Vibrio cholerae septicemia and meningitis in a neonate.Indian J Pediatr. 2002;69(10):909-10. DOI: 10.1007/ BF02723720 PMID: 12450305

44. Khan S, Kumar A, Meparambu D, Thomas S, Harichandran D, Karim S. Fatal non-01, non-0139 Vibrio cholerae septicaemia in a patient with chronic liver disease.J Med Microbiol. 2013;62(Pt 6):917-21. DOI: 10.1099/jmm.0.049296-o PMID: 23449872

45. Kontoyiannis DP, Calia KE, Basgoz N, Calderwood SB. Primary septicemia caused by Vibrio cholerae non-01 acquired on Cape Cod, Massachusetts.Clin Infect Dis. 1995;21(5):1330-3. DOI: 10.1093/clinids/21.5.1330 PMID: 8589171

46. Lalitha MK, Dayal U, Cherian AM. Non-agglutinating vibrio (non 0-1 V. cholerae) septicemia.Indian J Pathol Microbiol. 1986;29(1):27-30.PMID: 3781609

47. Laosombat V, Pruekprasert $P$, Wongchanchailert $M$. Non-0:1 Vibrio cholerae septicemia in thalassemia patients. Southeast Asian J Trop Med Public Health. 1996;27(2):411-3.PMID: 9280014

48. Lee MH, Leu HS, Huang SH. Bacteremic cellulitis caused by non- ${ }_{1}$ Vibrio cholerae: report of a case.J Formos Med Assoc. 1993;92(5):472-4.PMID: 8104603

49. Lopez-Brea M, Jimenez ML, de las Cuevas C, Alcala-Zamora J, Alonso P. Non-01 Vibrio cholerae septicaemia.Trans R Soc Trop Med Hyg. 1985;79(6):878-9. DOI: 10.1016/0035-9203(85)901518 PMID: 3832501

50. Lu B, Zhou H, Li D, Li F, Zhu F, Cui Y, et al. The first case of bacteraemia due to non-01/non-0139 Vibrio cholerae in a type 2 diabetes mellitus patient in mainland China. Int J Infect Dis. 2014;25:116-8. DOI: 10.1016/j.ijid.2014.04.015 PMID: 24905769

51. Lukinmaa S, Mattila K, Lehtinen V, Hakkinen M, Koskela M, Siitonen A. Territorial waters of the Baltic Sea as a source of infections caused by Vibrio cholerae non-01, non-0139: report of 3 hospitalized cases.Diagn Microbiol Infect Dis. 2006;54(1):1-6. DOI: 10.1016/j.diagmicrobio.2005.06.020 PMID: 16368474

52. Magnusson MR, Pegg SP. Vibrio cholerae non-01 primary septicaemia following a large thermal burn.Burns. 1996;22(1):44-7. DOI: 10.1016/0305-4179(95)00077-1 PMID: 8719316

53. Mannion PT, Mellor S. Unreviewed reports.Br Med J (Clin Res Ed). 1986;292(6518):450. DOI: 10.1136/bmj.292.6518.450 PMID: 20742605

54. Marek A, Inkster T, Anderson E, Jenkins C, Boyd J, Kerr S, et al. Non-toxigenic Vibrio cholerae bacteraemia: case report and review of the literature. J Med Microbiol. 2013;62 (Pt 9):1357-9. DOI: 10.1099/jmm.0.060400-0 PMID: 23722436

55. Mattics C. An inland water source of Vibrio cholerae responsible for sepsis.Clin Microbiol Newsl. 1989;11(7):54-6. DOI: 10.1016/0196-4399(89)90011-1

56. McCleskey FK, Hastings JR, Winn RE, Adams ED. Non-01 Vibrio cholerae bacteremia--complication of a LeVeen shunt.Am J Clin Pathol. 1986;85(5):644-6. DOI: 10.1093/ajcp/85.5.644 PMID: 3706203

57. Naidu LS, Bakerman PR, Saubolle MA, Lewis K. Vibrio cholerae non-0:1 meningitis in an infant.Pediatr Infect Dis J. 1993;12(10):879-81. DOI: 10.1097/00006454-199310000-00016 PMID: 8284127

58. Namdari H, Klaips CR, Hughes JL. A cytotoxin-producing strain of Vibrio cholerae non-01, non-0139 as a cause of cholera and bacteremia after consumption of raw clams.J Clin Microbiol. 2000;38(9):3518-9.PMID: 10970422

59. Newman C, Shepherd M, Woodard MD, Chopra AK, Tyring SK. Fatal septicemia and bullae caused by non-01 Vibrio cholerae.J Am Acad Dermatol. 1993;29(5 Pt 2):909-12. DOI: 10.1016/01909622(93)70269-Y PMID: 8408840 6o. Patel NM, Wong M, Little E, Ramos AX, Kolli G, Fox KM, et al. Vibrio cholerae non-01 infection in cirrhotics: case report and literature review. Transpl Infect Dis. 2009;11(1):54-6. DOI: 10.1111/j.1399-3062.2008.00339.x PMID: 18811633

61. Petsaris O, Nousbaum JB, Quilici ML, Le Coadou G, Payan C, Abalain ML. Non-01, non-0139 Vibrio cholerae bacteraemia in a cirrhotic patient.J Med Microbiol. 2010;59(Pt 10):1260-2. DOI: 10.1099/jmm.0.021014-o PMID: 20616193

62. Phetsouvanh R, Nakatsu M, Arakawa E, Davong V, Vongsouvath M, Lattana 0 , et al. Fatal bacteremia due to immotile Vibrio cholerae serogroup 021 in Vientiane, Laos - a case report. Ann Clin Microbiol Antimicrob. 2008;7(1):10. DOI: 10.1186/14760711-7-10 PMID: 18439249

63. Phu Huong Lan N, Vu Thieu NT, Thi Thu YN, Dung LT, Thanh TH, Campbell Jl, et al. Two cases of non-toxigenic Vibrio cholerae non- $0_{1}$, non-0139 bacteremia in Ho Chi Minh City. J Clin Microbiol. 2014.

64. Piersimoni C, Morbiducci V, Scalise G. Non-01 Vibrio cholerae gastroenteritis and bacteraemia.Lancet. 1991;337(8744):791-2. DOI: 10.1016/0140-6736(91)91409-N PMID: 1672411

65. Pitrak DL, Gindorf JD. Bacteremic cellulitis caused by nonserogroup $\mathrm{O}_{1}$ Vibrio cholerae acquired in a freshwater inland lake.J Clin Microbiol. 1989;27(12):2874-6.PMID: 2592550

66. Platia E, Vosti KL. Noncholera vibrio septicemia.West J Med. 1980;132(4):354-7.PMID: 7385839

67. Poulos JE, Cancio M, Conrad P, Nord HJ, Altus P. Non 0-1 Vibrio cholerae septicemia and culture negative neutrocytic ascites in a patient with chronic liver disease.J Fla Med Assoc. 1994;81(10):676-8.PMID: 7798872

68. Rabadan PM, Vilalta E. Non-0:1 Vibrio cholerae bacteremia.Rev Infect Dis. 1989;11(4):667. DOI: 10.1093/clinids/11.4.667 PMID: 2638813

69. Raju AZ, Mathai D, Jesudasan M, Suresh M, Kaur A, Abraham OC, et al. Nonagglutinable Vibrio cholerae septicaemia. J Assoc Physicians India. 1990;38(9):665-6.PMID: 2266091

70. Restrepo D, Huprikar SS, VanHorn K, Bottone EJ. $\mathrm{O}_{1}$ and non- $\mathrm{O}_{1}$ Vibrio cholerae bacteremia produced by hemolytic strains. Diagn Microbiol Infect Dis. 2006;54(2):145-8. DOI: 10.1016/j. diagmicrobio.2005.08.008 PMID: 16426794

71. Rubin LG, Altman J, Epple LK, Yolken RH. Vibrio cholerae meningitis in a neonate.J Pediatr. 1981;98(6):940-2. DOI: 10.1016/So022-3476(81)80596-3 PMID: 7229800

72. Rudensky B, Marcus EL, Isaacson M, Lefler E, Stamler B, Sechter I. Non-O group 1 Vibrio cholerae septicemia in Israel. Isr J Med Sci. 1993;29(1):54-5.PMID: 8454453

73. Safrin S, Morris JG, Adams M, Pons V, Jacobs R, Conte JE. Non-O:1 Vibrio cholerae bacteremia: case report and review.Rev Infect Dis. 1988;10(5):1012-7. DOI: 10.1093/ clinids/10.5.1012 PMID: 3055182

74. Shelton CH, Martino RL, Ramsey KM. Recurrent non-0:1 Vibrio cholerae bacteremia in a patient with multiple myeloma.Cancer. 1993;72(1):105-7. DOI: 10.1002/1097-0142(19930701)72:1<105::AID CNCR2820720120>3.0.CO;2-4 PMID: 8508394

75. Siegel MI, Rogers AI. Fatal non-01 Vibrio cholerae septicemia in chronic lymphocytic leukemia.Gastroenterology. 1982;83(5):1130-1.PMID: 7117796

76. Strumbelj I, Prelog I, Kotar T, Dovecar D, Petras T, Socan M. A case of Vibrio cholerae non-01, non-0139 septicaemia in Slovenia, imported from Tunisia, July 2005. Euro Surveill. 2005;10(10):E051020.6.PMID: 16790890

77. Stypulkowska-Misiurewicz H, Pancer K, Roszkowiak A. Two unrelated cases of septicaemia due to Vibrio cholerae non-01, non-0139 in Poland, July and August 2006. Euro Surveill. 2006;11(11):E061130.2.PMID: 17213560

78. Suankratay C, Phantumchinda K, Tachawiboonsak W, Wilde H. Non-serogroup 0:1 Vibrio cholerae bacteremia and cerebritis. Clin Infect Dis. 2001;32(7):E117-9. DOI: 10.1086/319596 PMID: 11264049

79. Tan KK, Sin KS, Ng AJ, Yahya H, Kaur P. Non-O1 Vibrio cholerae septicaemia: a case report.Singapore Med J. 1994;35(6):648-9. PMID: 7761898

80. Thisyakorn U, Reinprayoon S. Non-01 Vibrio cholerae septicemia: a case report. Southeast Asian J Trop Med Public Health. 1990;21(1):149-50.PMID: 2402675

81. Thomas M, Cherian T, Raghupathy P. Non-0:1 Vibrio cholerae bacteremia and peritonitis in a patient with nephrotic syndrome.Pediatr Infect Dis J. 1996;15(3):276-7. DOI: 10.1097/00006454-199603000-00025 PMID: 8852924

82. Toeg A, Berger SA, Battat A, Hoffman M, Yust I. Vibrio cholerae bacteremia associated with gastrectomy.J Clin Microbiol. 1990;28(3):603-4.PMID: 2324281 
83. Wang K, Chao CH, Liu IM, Liu CY. Non-0:1 Vibrio cholerae bacteremia: a case report and literature review.Zhonghua Yi Xue Za Zhi (Taipei). 1991;48(3):232-6.PMID: 1657343

84. West BC, Silberman R, Otterson WN. Acalculous cholecystitis and septicemia caused by non-01 Vibrio cholerae: first reported case and review of biliary infections with Vibrio cholerae.Diagn Microbiol Infect Dis. 1998;30(3):187-91. DOI: 10.1016/S0732-8893(97)00235-6 PMID: 9572025

85. Wiström J. A case of non-0:1 Vibrio cholerae bacteremia from northern Europe.J Infect Dis. 1989;160(4):732. DOI: 10.1093/ infdis/160.4.732 PMID: 2794570

86. Wiwatworapan W, Insiripong S. Non-01/non-0139 Vibrio cholerae septicemia with peritonitis. Southeast Asian J Trop Med Public Health. 2008;39(6):1098-101.PMID: 19062702

87. Yang CC, Lee BJ, Yang SS, Lin YH, Lee YL. A case of non- $0_{1}$ and non-0139 Vibrio cholerae septicemia with endophthalmitis in a cirrhotic patient.Jpn J Infect Dis. 2008;61(6):475-6.PMID: 19050358

88. Youmbissi JT, Malik TQ, Ajitkumar S, Rafi A, Al Kursany IA, Karkar A. Non-01 Vibrio choleraesepticemia and peritonitis complicating peritoneal dialysis.Infect Med. 2003;20(3):160-2.

89. Young CC, Chuang YC, Young CD. Non-0:1 Vibrio cholerae bacteremia: report of two cases.Kansenshogaku Zasshi. 1991;65(11):1479-83. DOI: 10.11150/ kansenshogakuzasshi1970.65.1479 PMID: 1791351

90. Ko WC, Chuang YC, Huang GC, Hsu SY. Infections due to non- $0_{1}$ Vibrio cholerae in southern Taiwan: predominance in cirrhotic patients.Clin Infect Dis. 1998;27(4):774-80. DOI: 10.1086/514947 PMID: 9798033

91. Lee YL, Hung PP, Tsai CA, Lin YH, Liu CE, Shi ZY. Clinical characteristics of non-01/non-0139 Vibrio cholerae isolates and polymerase chain reaction analysis of their virulence factors.J Microbiol Immunol Infect. 2007;40(6):474-80.PMID: 18087626

92. Lin CJ, Chiu CT, Lin DY, Sheen IS, Lien IM. Non-01 Vibrio cholerae bacteremia in patients with cirrhosis: 5 -yr experience from a single medical center.Am J Gastroenterol. 1996;91(2):336-40.PMID: 8607503

93. Trubiano JA, Lee JY, Valcanis M, Gregory J, Sutton BA, Holmes NE. Non-O1, non-O139 Vibrio cholerae bacteraemia in an Australian population.Intern Med J. 2014;44(5):508-11. DOI: 10.1111/imj.12409 PMID: 24816311

94. Tsai YH, Huang TJ, Hsu RW, Weng YJ, Hsu WH, Huang KC, et al. Necrotizing soft-tissue infections and primary sepsis caused by Vibrio vulnificus and Vibrio cholerae non-01. J Trauma. 2009;66(3):899-905. DOI: 10.1097/TA.obo13e31816a9ed3 PMID: 19276771

95. Yang Cl, Wang CS, Lu PL, Chen TC, Chen YH, Huang MS, et al. Bullous cellulitis in cirrhotic patients--a rare but lifethreatening infection caused by non-01, non-0139 Vibrio cholerae bacteraemia. J Med Microbiol. 2011;60(Pt 6):861-2. DOI: 10.1099/jmm.0.024497-0 PMID: 21292862

96. Sterk A, Schets FM, de Roda Husman AM, de Nijs T, Schijven JF. Effect of Climate Change on the Concentration and Associated Risks of Vibrio Spp. in Dutch Recreational Waters. Risk Anal. 2015;35(9):1717-29. DOI: 10.1111/risa.12365 PMID: 25809307

97. Pfeffer CS, Hite MF, Oliver JD. Ecology of Vibrio vulnificus in estuarine waters of eastern North Carolina.Appl Environ Microbiol. 2003;69(6):3526-31. DOI: 10.1128/AEM.69.6.35263531.2003 PMID: 12788759

98. Frank C, Littman M, Alpers K, Hallauer J. Vibrio vulnificus wound infections after contact with the Baltic Sea, Germany. Euro Surveill. 2006;11(8):E060817.1.PMID: 16966781

99. Oishi H, Ura Y, Mitsumizo S, Nakashima M. [A collective review of Vibrio vulnificus infection in Japan]. Kansenshogaku Zasshi. 2006;80(6):680-9. DOI: 10.11150/ kansenshogakuzasshi1970.80.680 PMID: 17176855

100. Hor LI, Chang TT, Wang ST. Survival of Vibrio vulnificus in whole blood from patients with chronic liver diseases: association with phagocytosis by neutrophils and serum ferritin levels.J Infect Dis. 1999;179(1):275-8. DOI: 10.1086/314554 PMID: 9841854

101. Ceccarelli D, Chen A, Hasan NA, Rashed SM, Huq A, Colwell RR. Vibrio cholerae non-01/non-0139 carrying multiple virulence factors and V. cholerae $0_{1}$ in the Chesapeake Bay, Maryland. Appl Environ Microbiol. 2015.

102. Cinar HN, Kothary M, Datta AR, Tall BD, Sprando R, Bilecen K, et al. Vibrio cholerae hemolysin is required for lethality, developmental delay, and intestinal vacuolation in Caenorhabditis elegans. PLoS One. 2010;5(7):e11558. DOI: 10.1371/journal.pone.0011558 PMID: 20644623

\section{License and copyright}

This is an open-access article distributed under the terms of the Creative Commons Attribution (CC BY 4.0) Licence. You may share and adapt the material, but must give appropriate credit to the source, provide a link to the licence, and indicate if changes were made.

This article is copyright of the authors, 2016. 